Abstracta Iranica Abstracta Iranica

Revue bibliographique pour le domaine irano-aryen

Volume 32-33 | 2013

Comptes rendus des publications de 2009-2010

\title{
M. A. Amir-Moezzi, J.-D. Dubois, C. Jullien, F. Jullien (eds.). Pensée grecque et sagesse d'Orient. Hommage à Michel Tardieu
}

\section{Rédaction}

\section{(2) OpenEdition}

1 Journals

\section{Édition électronique}

URL : http://journals.openedition.org/abstractairanica/39926

DOI : 10.4000/abstractairanica.39926

ISSN : 1961-960X

Éditeur :

CNRS (UMR 7528 Mondes iraniens et indiens), Éditions de l'IFRI

\section{Édition imprimée}

Date de publication : 1 décembre 2013

ISSN : 0240-8910

Référence électronique

Rédaction, « M. A. Amir-Moezzi, J.-D. Dubois, C. Jullien, F. Jullien (eds.). Pensée grecque et sagesse d'Orient. Hommage à Michel Tardieu », Abstracta Iranica [En ligne], Volume 32-33 | 2013, document 2, mis en ligne le 01 juillet 2016, consulté le 26 septembre 2020. URL : http://journals.openedition.org/ abstractairanica/39926 ; DOI : https://doi.org/10.4000/abstractairanica.39926

Ce document a été généré automatiquement le 26 septembre 2020.

Tous droits réservés 


\title{
M. A. Amir-Moezzi, J.-D. Dubois, C. Jullien, F. Jullien (eds.). Pensée grecque et sagesse d'Orient. Hommage à Michel Tardieu
}

\author{
Rédaction
}

\section{RÉFÉRENCE}

M. A. Amir-Moezzi, J.-D. Dubois, C. Jullien, F. Jullien (eds.). Pensée grecque et sagesse d'Orient. Hommage à Michel Tardieu. Turnhout, Brepols, 756 p. (Bibliothèque de l'École des Hautes Études 142)

1 Cet hommage rendu au professeur Michel Tardieu à l'occasion de son $70^{\mathrm{e}}$ anniversaire réunit des contributions très diversifiées qui illustrent les différents domaines qu'il s'est plu à fréquenter. Plusieurs articles ont trait au manichéisme : vie sociale à Kellis, démonologie iranienne dans la doctrine manichéenne, origines de Mani, relations entre manichéens et marcionites chez Ephrem, iconographie. D'autres traitent plus spécifiquement du monde iranien et de l'Asie centrale : traitement de la figure de Zoroastre, littérature persane, histoire et correspondance des mongols... Relevons également des contributions sur les christianismes orientaux, à travers des corpus linguistiques variés (domaine syriaque, arménien, copte).

Table des matières :

- Denise Aigle, « Les correspondances adressées par Hülegü au prince ayyoubide al-Malik al-Nāṣir Yūsuf. La construction d'un modèle » ;

- Mohammed-Ali Amir-Moezzi, «L'ascension céleste du prophète Muhammad: note bibliographique »;

- Polymnia Athanassiadi, « Le traitement du mythe : de l'empereur Julien à Proclus »;

-Jean-Christophe Attias, « Comparatisme et "religions du Livre" : la voie étroite?»; 
- Robert Beylot, «Un témoin éthiopien inédit du Gradus 5 de Jean Climaque, Collegeville Emml 1939, folio $102 \mathrm{r}^{\circ}-113 \mathrm{v}^{\circ} »$;

- Anne Boud'hors, «Vêtements lacérés et piétinés dans un sermon de Chenouté » ;

- Edina Bozoky, « Historiolae apocryphae : les charmes narratifs au Moyen Âge »;

- Françoise Briquel-Chatonnet, «Une jeune fille changée en jeune homme. Homélie sur un miracle survenu dans le monastère de Qartmin, dans le Tur Abdin »;

- Annick Charles-Saget, « Présence ( $\pi \alpha \rho o v \sigma i ́ \alpha)$ chez Plotin »;

- Pierre Chuvin, « Réception d'un oracle de Claros en milieu chrétien »;

- Emily Cottrell, «L'autobiographie de Zoroastre »;

- Alain Desreumaux, «L'environnement de l'Apocalypse de Paul. À propos d'un nouveau manuscrit syriaque de la Caverne des trésors";

- Gilles Dorival, « Du fondamentalisme au littéralisme »;

- Jean-Daniel Dubois, «Vivre dans la communauté manichéenne de Kellis: une lettre de Makarios, le papyrus Kell. Copt. $22 »$;

- Charles-Henri de Fouchécour, «Noé, avertisseur et prophète universel dans la tradition persane ";

- Françoise Frontisi-Ducroux, «Le prince et le faux-prophète. Quelques cas de Lectiones vitiosae en iconographie grecque ";

- Claude Gilliot, « La vision de Dieu dans l'Au-delà: exégèse, tradition et théologie en islam »;

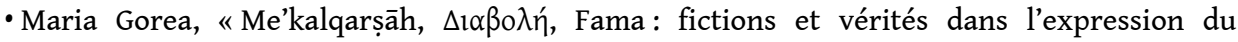
discours accusateur»;

- Frantz Grenet, «Démons iraniens et divinités grecques dans le manichéisme : à propos de quelques passages de textes sogdiens de Turfan (avec une Note additionnelle par Nicholas Sims-Williams)»;

- Rika Gyselen, «Sources arméniennes et sources primaires sassanides: harmonie et dissonance »;

- Henri Hugonnard-Roche, « Platon syriaque »;

- Christelle Jullien, Philippe Gignoux, «Les mages christianisés. Reconstruction historique et onomastique des listes nominales syriaques »;

- Florence Jullien, «La "triade" de al-Ḥīra» ;

- Jean Kellens, « Zarathushtra : métamorphoses d'un prophète »;

- Alain Le Boulluec, « Jésus selon Les Homélies clémentines : du vrai prophète au prince de l'âge à venir » ;

- Jean-Claude Métrope, «L'ontologie et la cosmogonie du système de Basilide (Alexandrie, II ${ }^{\mathrm{e}}$ siècle après Jésus-Christ)»;

- Simon Mimouni, «Les origines ethnico-religieuses de Mani ?»;

- Guy Monnot, «Trône et royauté de Dieu dans l'islam »;

- Alice Mouton, «Le "mauvais œil" d'après les textes cunéiformes hittites et mésopotamiens »;

- Chiemi Nakano, «Des rapports entre les marcionites et les manichéens dans un corpus éphrémien : S. Ephrem's Prose Refutations of Mani, Marcion, and Bardaisan» ;

- Marie-Joseph Pierre, «Unité de lieu dans la vie et l'œuvre de Jean Climaque : éléments de topographie sinaïtique et d'histoire religieuse »;

- Aline Pourkier, «Épiphane de Salamine et l'hellénisme » ;

- Lucie Rault, «À la recherche de la musique antérieure »;

- Su-Min Ri, « Mar Ephrem, la femme samaritaine et les fragments d'Héracléon »;

- Odile Ricoux, «L'étoile apparue aux Mages et la Vierge à l'Enfant : analyse des traditions »;

- Christian Robin, « ‘Ammīanas, dieu de Khawlān (Yémen)» ; 
- Lucia Saudelli, « Les fragments d'Héraclite et l'influence gnostique chez Plotin, Enn. IV 8 [6], $1 »$;

- John Scheid, « Mithra agriculteur. Images et interprétations »;

- Madeleine Scopello, «Les anges dans l'Évangile de Judas : aperçu préliminaire » ;

- Helmut Seng, «Scylla und Tarpeia. Kallimacheisches und Anti-Kallimacheisches in der pseudovergilischen Ciris und der Tarpeia-Elegie des Properz »;

- Gulia Sfameni Gasparro, "The "god of gods", Lord and and Begetter of all, in the Papyrus Graecae Magicae (PGM): between theology and magic »;

- Luciana Gabriela Soares Santoprete, «La question de la localisation des intelligibles chez les philosophes païens des premiers siècles de l'ère chrétienne »;

- Brigitte Tambrun, « Pourquoi Cosme de Médicis a fait traduire Platon?»;

- Javier Teixidor, «Brèves notions de philosophie de Sylvain de Qardu »;

- Anna van den Kerchove, «Le cri du démon : à propos d'une restitution dans le Kephalaion $6 »$;

- Gilles Veinstein, «Le janissaire et l'islamologue : un commentaire du chapitre des kavânîn-i yeniçeriyân sur le devşirme »;

-Yutaka Yoshida, «A Newly Recognized Manichaean Painting: Manichaean Daēnā from Japan »;

- Michela Zago, « Le pneuma éloquent. Un parallèle entre le papyrus Mimaut et NHC VI, 6 ».

\section{AUTEURS}

\section{RÉDACTION}

Directeur de la revue et secrétariat (Paris) 